\title{
Educational presorting as a cause of occupational segregation
}

Citation for published version (APA):

Borghans, L., \& Groot, L. M. J. (1999). Educational presorting as a cause of occupational segregation. Researchcentrum voor Onderwijs en Arbeidsmarkt, Faculteit der Economische Wetenschappen. ROA Research Memoranda No. 3E https://doi.org/10.26481/umaror.199903E

Document status and date:

Published: 01/01/1999

DOI:

10.26481/umaror.199903E

Document Version:

Publisher's PDF, also known as Version of record

\section{Please check the document version of this publication:}

- A submitted manuscript is the version of the article upon submission and before peer-review. There can be important differences between the submitted version and the official published version of record.

People interested in the research are advised to contact the author for the final version of the publication, or visit the DOI to the publisher's website.

- The final author version and the galley proof are versions of the publication after peer review.

- The final published version features the final layout of the paper including the volume, issue and page numbers.

Link to publication

\footnotetext{
General rights rights.

- You may freely distribute the URL identifying the publication in the public portal. please follow below link for the End User Agreement:

www.umlib.nl/taverne-license

Take down policy

If you believe that this document breaches copyright please contact us at:

repository@maastrichtuniversity.nl

providing details and we will investigate your claim.
}

Copyright and moral rights for the publications made accessible in the public portal are retained by the authors and/or other copyright owners and it is a condition of accessing publications that users recognise and abide by the legal requirements associated with these

- Users may download and print one copy of any publication from the public portal for the purpose of private study or research.

- You may not further distribute the material or use it for any profit-making activity or commercial gain

If the publication is distributed under the terms of Article $25 \mathrm{fa}$ of the Dutch Copyright Act, indicated by the "Taverne" license above, 


\section{Educational presorting as a cause of occupational segregation}

ROA-RM-1999/3

Lex Borghans* and Loek Groot**

* Research Centre for Education and the Labour Market

** Department of Social Economics (FSW) Utrecht University

Research Centre for Education and the Labour Market

Faculty of Economics and Business Administration

Maastricht University

Maastricht, December 1999 
ISBN 90-5321-274-4

SEC00.043/LB 


\section{Contents}

Page

Abstract

1 Introduction

2 The measurement of segregation

3 The relation between educational and occupational segregation

4 Empirical Results

5 Conclusions

References

25 



\section{Abstract}

This article concentrates on the measurement of both occupational and educational segregation between the men and women of the Dutch labour force. The majority of studies which have been conducted in this area are rather one-sided, concentrating on occupational segregation alone. However, occupational segregation can be split into three components. The first component concerns presorting as a consequence of the different educational choices made by boys and girls. The second component concerns postsorting (given their educational status), as a result of the differing occupational choices and opportunities for promotion between men and women during their careers. If men and women with the same educational background are directed towards different occupations, then postsorting may add to the occupational segregation which was already induced by the earlier educational segregation. This kind of postsorting increases the gap between occupational and educational segregation. The third component, which we refer to as reintegration is also a kind of postsorting, narrowing the gap between occupational and educational segregation. This occurs when men with a 'male type' of education and women with a 'female type' of education come together in one occupation. Given that educational segregation of the labour force is fixed in the short term, reintegration is the only effective, but probably difficult affirmative action program to reduce occupational segregation in the short term. More usual programs are ineffective and can even be counterproductive. After using the Duncan and Duncan segregation index we construct new segregation indices which measure the relative importance of pre- and postsorting in the occupational segregation more accurately. A more detailed insight into these three components is relevant when choosing the policy instruments needed to achieve equal employment opportunities for men and women. 


\section{Introduction}

In the economic analysis of men and women's respective positions in the labour market much attention has been paid to the measurement of occupational segregation (hereafter abbreviated as OS), i.e. the extent to which women's jobs differ from those of men. Although the number of studies measuring segregation is quite large, most of them limit themselves to the measurement of OS only (see for example Boisso (1994), Watts and Rich (1993), King (1992), Karmel and MacLachlan (1988), Albelda (1986) and Beller (1982)). At best, OS is combined with educational statistics in a rather loose way. A systematic treatment connecting educational segregation (henceforth ES) and OS is lacking. Therefore, the current state of affairs is that we have a good understanding of the incidence of OS, but know much less about the way it is brought about. Differing educational choices act as constraints on the future occupational choice. As well as this educational induced segregation, there is also the segregation which occurs when boys and girls with the same educational background end up in different occupations. Finally, how important is reintegration, i.e. men and women with differing educational backgrounds ending up in the same jobs? These are the questions which this article attempts to answer.

We define presorting as the extent to which different educational distributions of boys and girls give rise to or cause different occupational distributions of men and women. ${ }^{1}$ The phenomenon of presorting will be stronger, the stronger the link between education and occupation. If there is no connection between education and occupation, measuring ES in order to explain OS would be of no use at all. ES and OS would be independent of each other, and no presorting would take place.

Postsorting is defined as the extent to which, given the ES, men and women end up in different occupations. Suppose that there is no ES which implies that presorting cannot take place. OS or postsorting can still arise if men and women with the same educational background end up in different occupations. This will increase OS between the sexes, adding to that expected when presorting takes place. There might, however, be a compensating tendency in the transition from school to the labour market. Women with a 'female' educational background might find jobs in the same occupations as men who followed a typical 'male' type of education. This is a kind of negative postsorting, but we prefer to call this phenomenon reintegration. The relationship between ES and OS therefore possibly consists of both diverging and converging tendencies towards an otherwise equal occupational distribution. This implies that, given the degree of ES (which can be considered as fixed in the short term), there are still possibilities to decrease overall OS. A very effective way to do this is to provide employers with incentives to hire female (male) workers with an educa-

1. Alternatively, one may wish to define presorting as the extent to which boys and girls choose different educational careers, irrespective of its effects on the occupational segregation later on. However, this is just ES proper. 
tional background which is predominantly female (male) in nature for typical male (female) type jobs. For instance, engineers on trains and trams and bus drivers are traditionally male jobs. Workers for these jobs are usually recruited from those engaged in education which is male in nature, for example, lower technical vocational education. Since very few women are enrolled in this type of education, one can reduce $O S$ in this segment of the labour market (and elsewhere) by recruiting and training women from female types of education (i.e. types of education in which the share of women exceeds the share of females in the total labour force) for these jobs. However, an affirmative action program (AAP) which aims at recruiting more women with a lower technical vocational education for the transport jobs does not reduce OS, since it forces employers elsewhere in the labour market to take less women with this educational background for other technical jobs.

With this in mind, we can distinguish between two types of AAP's, one ineffective and one effective in the short term. Ineffective AAP's are those which do not take into account the fact that the ES of the labour force cannot be changed immediately. These programs require more women in male dominated jobs, even if the women who possess the skills required for the job are short in supply. Effective AAP's however are those which fully acknowledge the ES, but which try to neutralize its impact on OS, e.g. by offering special training programs to members of the underrepresented group in order to enable them to get access to these jobs. ${ }^{2}$ Examples of both are given in Section IV.

The structure of the article is as follows. Section II contains an analysis of the well-known Duncan and Duncan segregation or dissimilarity index along with the first empirical results. In Section III we continue the analysis by linking OS to ES in order to disentangle the different components which are responsible for the gap. In Section IV empirical results, based on Dutch labour force survey's from 1979 until 1994, are provided concerning the components of the segregation process which were distinguished in the analytical section. Conclusions can be found in the final section.

\section{The measurement of segregation}

Most analyses of OS are related to the so-called Duncan and Duncan dissimilarity index [6]:

(1)

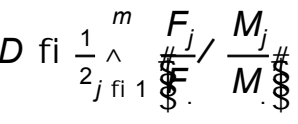

2. If the cause of segregation is discrimination, this strategy is of no use. Here though we implicitly assume that the cause is more in line with human capital theory. 
where:

$\mathrm{F}_{\mathrm{j}}=$ the number of women working in job $j$

$\mathrm{F}$. = the total number of women working

$\mathrm{M}=$ the number of men working in job $j$

$M .=$ the total number of men working.

This index measures the fraction of women that have to change their job in order to equalise female and male occupational distributions. ${ }^{3}$ As has been argued by Karmel and Maclachlan (1988), Watts (1992) and others, this index has two disadvantages. Firstly, it measures the number of job changes required to achieve an equal distribution as a fraction of the total number of women or men, while it would be more appropriate to relate the number of changes needed to the total number of workers, male or female. Secondly, and more importantly, the changes that are generally required in order to achieve an equal distribution will change the distribution of workers over all jobs. ${ }^{4}$ The Duncan and Duncan index therefore not only measures the required changes which will equalise the female distribution with the male distribution, but furthermore these changes affect the size of the different occupational categories, that is, the occupational distribution itself.

To acquire a more appropriate index, as introduced by Karmel and Maclachlan (1988) and Groot (1990), imagine that both men and women change jobs in such a way that the distribution of workers over all jobs is unaffected, and these changes have to be related to the total number of workers. Denoting the number of people working in job $j$ by $T_{j}$ (with $T_{j}=F_{j}+M_{j}$ ) and the total number of people working by $\mathrm{T}$. $(\mathrm{T} .=\mathrm{F} .+\mathrm{M}$.), the target number of female workers in job $j$ equals $\frac{F}{T} T_{j}$ and for the male $\frac{M}{T} T_{j}$. Here, we consider the number of workers in each job (the occupational distribution) as given. Therefore, the adjusted segregation index equals:

Since

(2)

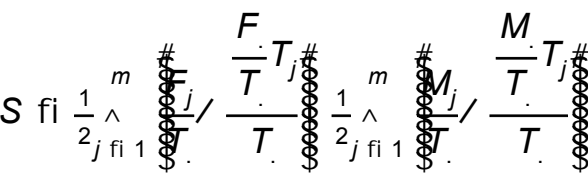

and due to the absolute operators and the symmetry of both components in (2),

3. Note that the segregation indexes discussed in this paper only concern men and women who are working. Segregation between employed, unemployed and people who are not participating is not analyzed. By treating the unemployed or non-participating as an occupational category, these groups could be integrated in the analyses.

4. We use jobs and occupations interchangeably. 
(3)

$$
\text { 县 } \frac{\frac{F}{T}}{T} \frac{T_{j}}{T}
$$

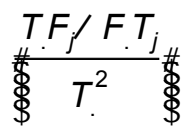

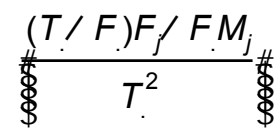

$\frac{M F_{j} \square F M_{j}}{\text { 自 }^{2}} T^{2}$ 自

$\frac{F M}{T^{2}} \frac{F_{j}}{F_{F}} \square \frac{M_{j}}{M}$ 貝

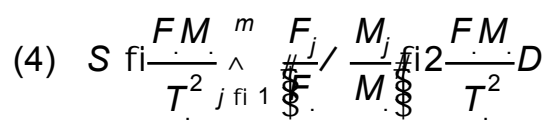

Defining $\theta \square F M / T^{2}$. gives $S \square 2 \theta D$, a relationship that will be used throughout this paper. ${ }^{56}$

If the number of men is equal to the number of women employed, then $\theta \square 1 / 4$, and hence $S \square D / 2$ as might be expected since it is not relevant whether men or women change jobs (the required job-changes are now presented as a fraction of the total work force, which here is equal to twice the female work force). Despite the two improvements which have been made on the Duncan and Duncan index, this new index also suffers from two different short-comings. Firstly, if the overall employment ratio between both sexes is not unity, then the adjusted segregation index is less than half the Duncan and Duncan index, as the majority of job changes occur in the smallest group. For instance, if only $10 \%$ of the total work force is female the outcome for $S$ can never exceed $2 \theta$. S will equal $2 \theta$ when OS is complete, an event that is highly unlikely. ${ }^{7}$ For this reason the adjusted segregation index

5. See Borghans and Groot (1998) for the complete derivation of (2).

6. Blackburn, Siltanen and Jarman (1995) show that these indices can be expressed as functions of only four basic numbers: the number of male and female workers in male and female occupations, in which (fe)male occupations are defined as occupations in which the fraction (fe)males is above the average for the whole labour market. The further analyses presented in this paper do however not allow for this simplification.

7. As an example, suppose all (fe)males are working in (fe)male jobs. To equalise the occupational distribution, 9 out of 10 female workers have to be directed towards male jobs and 1 out of 10 male workers must take up a female job. Since the female participation rate is assumed to be 
will increase if, all other things equal, the labour participation of women becomes more in line with that of men. This may seriously hamper the comparison of OS across countries with differing female labour participation rates. Secondly, the index when expressed as 'the percentage of job changes needed' fails to consider whether the workers involved in these job changes possess the educational skills that their new jobs require. We do not claim to solve these shortcomings, although we feel it is useful to acknowledge that they exist.

In order to investigate the link between ES and OS, data ${ }^{8}$ about the number of people in education $i$ and occupation $j$ are used. These numbers are denoted by $T_{i j}$, which can be divided into women and men with $T_{i j} \square F_{i j} \square M_{i j}$. Again, totals are denoted by a dot. The educational totals are $T_{i .} \square F_{i .} \square M_{i .}$, the occupational totals are $T_{j, j} \square F_{. j} \square M_{j}$ and the grand totals are $T . . \square F . . \square M_{. .}$. Of course, here $\theta \square F_{. .} M_{. .} / T_{. .}^{2}$.

By analogy with (4) the index for ES can be expressed as:

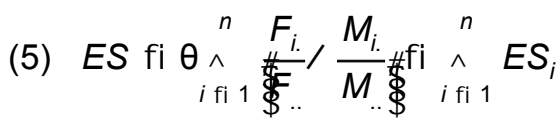

with

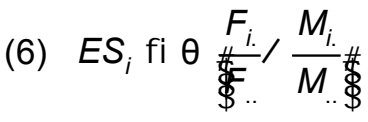

as the $i$-th component of the ES and

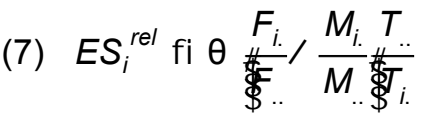

as the relative $i$-th component of the ES. ${ }^{9}$

$10 \%, 18 \%$ of the work force (which equals $2 \theta$ ) have to change jobs.

8. Data are taken from the Dutch labour force surveys of Statistics Netherlands (CBS). For 19791985 this is the so-called Arbeids-Krachten-Telling (AKT) covering approximately $2.5 \%$ of the labour force in 1979, 1983 and 1985 and 5\% in 1981. For 1993/94 the survey is called Enquête Beroeps-Bevolking (EBB). This survey covers approximately $1 \%$ yearly. For this reason a double year has been used, making coverage comparable with the former survey.

9. The factor $T / T_{i}$ is used here as a weight to counterbalance the relative importance of education i so that different educations become mutually comparable. If the number of people enrolled in $\mathrm{i}$ is small, the expression between the absolute operators is also small. Without the weight factor (as in (6)), we would get a very small outcome, even if ES in $i$ is assumed to be complete. 
Analogously, the OS can be defined as:

and total segregation

(TS) as:

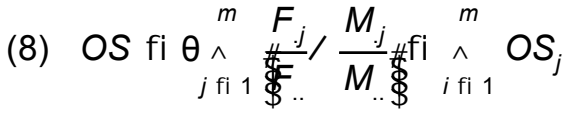

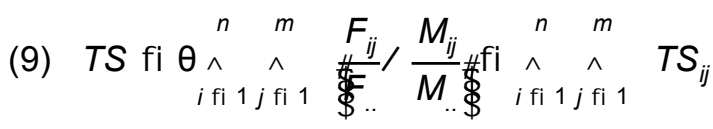

Table 1

Educational (ES) and occupational segregation (OS) on the Dutch labour market in 1979 to 1985 (source AKT, CBS)

$\begin{array}{ll}\text { ES } & \text { OS } \\ \% & \%\end{array}$

$\begin{array}{lll}1979 & 17.9 & 24.8 \\ 1981 & 18.5 & 25.2 \\ 1983 & 19.9 & 26.0 \\ 1985 & 20.8 & 25.9 \\ 1993 / 94 & 21.6 & 23.8\end{array}$

* The segregation indices are based on 49 occupational segments of the ROA occupational classification and 54 educational types (see Table 4).

Table 1 shows ES and OS for 1979 through to 1993/94. The figures indicate that OS is larger than ES. Groot (1990) suggested that ES can be regarded as the presorting of men and women by the educational system. Up until 1985 the trend seems indeed to suggest that the increase in segregation is mainly due to the increase in ES. However, while OS grew only gradually during the 1979-1983 period and decreased thereafter, ES continued to increase. ${ }^{10} \mathrm{~A}$ main reason for this increased ES is that many older people with only a primary education (including both men and women), leave the labour market through retirement or disability, and are replaced by young people who have at least an intermediate or higher vocational training, where ES is more likely to occur. However, this process only explains half of the increase in ES. For the purpose of our studies, it is important to note that

10. Similar trends can be found when using the Duncan and Duncan index. The increase in educational segregation is not therefore explained by an increase in female labour participation. 
the gap between OS and ES diminishes over time, and also that both are able to move independently, even in opposite directions. The figures therefore do not necessarily indicate a causal relationship between ES and OS. It is possible for ES to increase, and at the same time see the probability of women and men ending up in different occupations becoming less.

Thus, we argue that these findings do not necessarily imply that OS is primarily caused by ES. The route from ES to OS consists of two steps. Firstly, starting with a particular amount of ES, school-leavers with a certain educational background have to be distributed over the various occupations. Some traditionally male (female) occupations may decrease their contribution towards OS and TS by employing or recruiting more women (men) with the required education than is suggested by the existing fraction of women (men) already represented in this male type of education. On the other hand, however, other occupations will then have to increase their contribution towards segregation by employing the remaining group. It can be shown that this process of reshuffling will on average only increase OS and TS. ${ }^{11}$

Secondly, men from dominantly male and women from dominantly female types of education may come together in one occupation, since there are several educational routes leading to the same job. This process of reintegration can reduce OS significantly. This aspect of the relationship between ES and OS, usually ignored in the analysis of segregation, points to the possibility that men and women may follow different educational routes and ultimately end up with the same job (see the next section for more details). This allows for the possibility of reducing OS in the short term without any change in ES (e.g. by stimulating employers to recruite female (male) workers for typical male (female) jobs from predominantly female (male) types of education).

Table 2

Educational (ES), occupational (OS) and sectoral segregation (SS) of men and women in 1985

ES based on 54 educational types

Table 2 provides segregation indices for 1985 in which educations or occupations are classified differently. If the two-digit ISCED educational classification is replaced by a classification where only the educational level is taken into account, ES largely disappears.

11. See the example of an overambitious and ineffective affirmative action plan in section IV. 
Thus, employed women do not have lower educational levels than employed men. With a classification of educational subjects only, the segregation level remains almost the same. ES can therefore be identified as mainly subject segregation. Furthermore Table 2 shows that the assertion that ES inevitably passes on to OS through presorting is premature. In the final row of the table the occupational classification is replaced by a classification of the sectors of industry in which people work. The segregation over sectors is much lower than the segregation over occupations, and this particular example shows that it is impossible to regard ES a priori as presorting for segregation (whether occupational or sectoral) in the labour market. Evidently, if segregation is measured by sectors rather than by occupation, the matching process in the labour market was such that the ES did not pass on to sectoral segregation in 1985. Of course, the link between type of education and occupation differs from the link between the type of education and sector of industry. For example, those who receive a secretarial training will probably become secretaries working in all sectors of industry. But other types of education, for instance in hotel and catering, may exhibit a tight connection with a particular sector of industry. In the former ES will not pass on to sectoral segregation, while in the latter it will. Table 2 shows only that educational segregation does not necessarily pass on to either occupational or sectoral segregation.

To investigate the relationship between ES and OS it is necessary to relate ES to OS analytically, and to investigate this relationship empirically. The following section provides the analytical relationships, while section $\mathrm{V}$ provides the empirical results.

\section{The relation between educational and occupational segregation}

As a starting point for the analysis of the relationship between ES and OS, imagine that students from one type of education are distributed over all occupations in proportion to their educational sex ratios. This distribution which is induced by ES equals:

and

$$
F_{i j}^{e d u c} \square \frac{F_{i .}}{T_{i .}} T_{i j}
$$

$$
M_{i j}^{\text {educ }} \square \frac{M_{i .}}{T_{i .}} T_{i j} \square T_{i j} \square F_{i j}^{e d u c}
$$

In a distribution which obeys (10) and (11), so that for all $(\mathrm{i}, \mathrm{j}) F_{i j} \square F_{i j}^{\text {educ }}$, only presorting occurs (no postsorting takes place). In a world with ES which passes on fully to OS (complete presorting and no postsorting), the chance of a randomly selected woman ending up in $(i, j)$, given the number of workers in $(i, j)$, depends only on the fraction of women within education $\mathrm{i}$. This distribution will in general not be equal to the actual distribution $F_{i j}, M_{i j}$ and will also deviate from the 'ideal' or equal distribution in which female and male workers are 
distributed according to their overall ratio:

(12) $F_{i j}^{\text {equal }} \square \frac{F_{.:}}{T} T_{i j}$

and

(13) $M_{i j}^{\text {equal }} \square \frac{M_{*}}{T} T_{i j} \square T_{i j} \square F_{i j}^{\text {equal }}$

In what we term as the 'ideal' or 'equal' distribution, neither pre- or postsorting occurs, nor is there any ES or OS. The notion of the ideal distribution, or of $F_{i j}^{\text {equal }}$ and $M_{i j}^{\text {equal }}$, is important as an archimedean point in the measurement of segregation. The pre- and postsorting means that the actual $F_{i j}$ and $M_{i j}$ differ from their 'ideal' counterparts. The ideal distribution is that which can be expected in a world where there are no sex-related differences in educational choices or occupational opportunities. Given the number of workers in $(\mathrm{i}, \mathrm{j})$, the chance of a randomly selected woman ending up in $(\mathrm{i}, \mathrm{j})$ would in this case only depend on the overall female participation rate.

Given (12) and using the same procedure as in (3):

and therefore

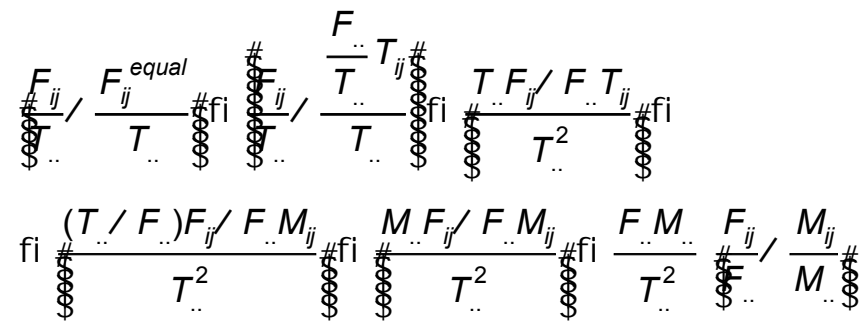

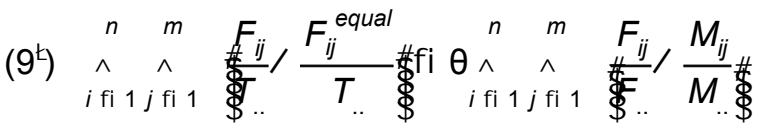

equals TS as defined by (9). TS thus measures the 'distance' between the actual and the ideal distribution.

The additional segregation (AS), that is the first component of postsorting during the transition from school to the labour market, given the educational distribution of men and women, is calculated by: 
(14)

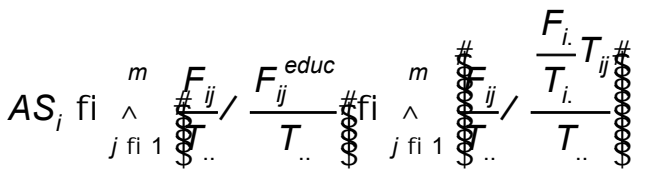

Relatively this index equals:

$$
A S_{i}^{r e l} \square A S_{i} \frac{T_{. .}}{T_{. i}}
$$

Based on this index per education type, an index of the total AS can be constructed:

(16) $A S \square \underset{i \square 1}{n} A S_{i}$

AS is an index which correctly expresses the first component of postsorting, with complete presorting as the baseline. With complete presorting, AS equals zero. ${ }^{12}$ It measures the distance between the actual distribution and the distribution which we would expect with complete presorting due to ES. What we have said so far seems to suggest that OS, i.e. the difference between the occupational distribution of women and men, can be decomposed into ES and postsorting. However, it does not necessarily hold that OS $\square$ ES $\square A S$. The nonnegativity of all three segregation indexes implies that OS $\square E S$. However, if we replace occupational by sectoral segregation as in the final row of Table 2, we see that this cannot be true since sectoral segregation is smaller than ES.

The reason why it is not possible to simply add AS to the ES is twofold. Firstly, the whole amount of ES does not necessarily pass fully on to OS. The extent to which ES passes to OS depends on the tightness of the link between the (mainly vocational) skills learned during formal schooling and the specific skills demanded for particular jobs. Secondly, this addition - if carried out correctly - relates to TS (see equations (9) and (19)), rather than OS.

12. Incomplete presorting requires some postsorting in the sense that some women and men with the same educational background are allocated differently over the various occupations. 
Figure 1

The six possible relative positions of $F_{i j}{ }^{\text {equal }}, F_{i j}{ }^{\text {educ }}$ and $F_{i j}$
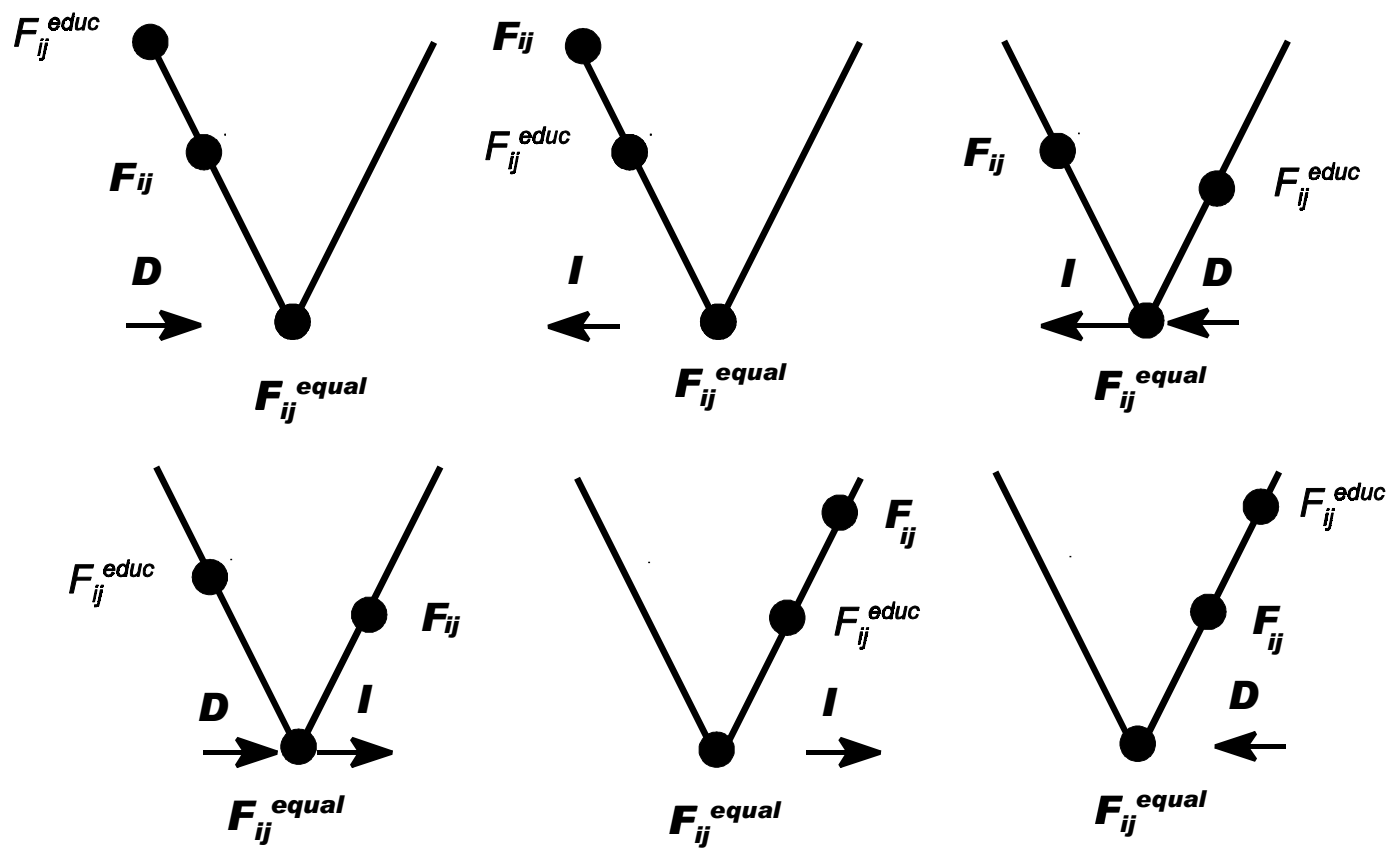

Increasing and decreasing segregation

The six possible positions of $F_{i j}^{\text {equal }}, F_{i j}^{\text {educ }}$, and $F_{i j}$ have been drawn in Figure 1 in order to disentangle the relationships between the different measures of segregation. The first row gives all the situations where women are underrepresented when compared to the ideal distribution $\left(F_{i j}\right.$ is to the left of $F_{i j}^{\text {equal }}$ ), while in the second row women are overrepresented ( $F_{i j}$ is to the right of $F_{i j}^{\text {equal }}$ ). By using (10) and (12):

$$
F_{i j}^{\text {educ }}>F_{i j}^{\text {equal }} @ \frac{F_{i .}}{T_{i .}}>\frac{F_{. .}}{T_{. .}}
$$

$F_{i j}^{\text {educ }}$ can thus only be to the right of $F_{i j}^{\text {equal }}$ if education $i$ is of a 'female type', that is if the educational ratio between women and men within $i$ is higher than the overall ratio of (employed) women and men. If $F_{i j}$ is to the left of $F_{i j}^{\text {educ }}$, then women are underrepresented compared to what would have been expected given the educational distribution of men and women (the third column and the upper section of the second column), while overrepresentation occurs in the first column and the lower section of the second column.

The distance $F_{i j}^{\text {equal }}$ to $F_{i j}^{\text {educ }}$ represents the effect of presorting. Postsorting as measured by AS relates to the distance $F_{i j}^{\text {educ }}$ to $F_{i j}$, and as indicated by the arrows at the foot of the 
diagrams, this can be an increase or a decrease. Both are movements away from the distribution induced by ES, but if the movement is towards the ideal distribution it counts as a decrease while any movement away from it represents an increase. The third section in the first row and the first section in the second row are the most interesting. These illustrate a kind of overshooting. In these cases, TS decreases at first and then increases again once $F_{i j}^{\text {equal }}$ has been passed.

Table 3 shows the contributions that the increases $I_{i j}$ and decreases $D_{i j}$ designated in figure 1 make to AS:

Table 3

The six possible orderings of $F_{i j}^{\text {educ }}, F_{i j}^{\text {equal }}$ and $F_{i j}$

$$
\begin{aligned}
F_{i j}^{\text {educ }}<\min \left[\mathbb{F}_{i j}, F_{i j}^{\text {equal } !} \quad\right. & F_{i j}^{\text {educ }}<\max \mathbb{F}_{i j}, F_{i j}^{\text {equal } !} \quad F_{i j}^{\text {educ }}>\max \left[\mathbb{F}_{i j}, F_{i j}^{\text {equal } !}\right. \\
& F_{i j}^{\text {educ }}>\min \left[\mathbb{F}_{i j}, F_{i j}^{\text {equal } !}\right.
\end{aligned}
$$

$F_{i j}<F_{i j}^{\text {equal }}\left\{\begin{array}{c}l_{i j} \square 0 \\ D_{i j} \square \frac{F_{i j} \square F_{i j}^{\text {educ }}}{T_{. .}}\end{array} \quad\left\{\begin{array}{c}l_{i j} \square \frac{F_{i j}^{\text {educ }} \square F_{i j}}{T_{. .}} \\ D_{i j} \square 0\end{array} \quad\left\{\begin{array}{c}I_{i j} \square \frac{F_{i j}^{\text {equal }} \square F_{i j}}{T_{. .}} \\ D_{i j} \square \frac{F_{i j}^{\text {educ }} \square F_{i j}^{\text {equal }}}{T_{. .}}\end{array}\right.\right.\right.$

$F_{i j}>F_{i j}^{\text {equal }}\left\{\begin{array}{c}I_{i j} \square \frac{F_{i j} \square F_{i j}^{\text {equal }}}{T_{. .}} \\ D_{i j} \square \frac{F_{i j}^{\text {equal }} \square F_{i j}^{\text {educ }}}{T_{. .}}\end{array}\left\{\begin{array}{c}I_{i j} \square \frac{F_{i j} \square F_{i j}^{\text {educ }}}{T .} \\ D_{i j} \square 0\end{array} \quad\left\{\begin{array}{c}I_{i j} \square 0 \\ D_{i j} \square \frac{F_{i j}^{\text {educ }} \square F_{i j}}{T_{. .}}\end{array}\right.\right.\right.$

By summing all the increases

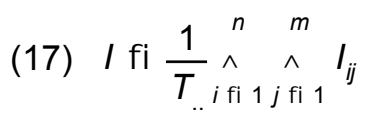

and all the decreases

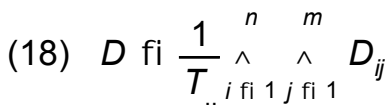


a direct consequence of these definitions is that:

(19) $\quad A S \square I \square D$

and

(20) TS $\square E S \square I \square D$

This implies that AS sums all the deviations, both increases and decreases, from what is expected given the educational distribution of men and women (that is, if only presorting and no postsorting occurs). This means that if a number of women with a particular education type are more than proportionaly represented in one job (as in the first two sections of the second row), it must also necessarily be the case that there are other jobs where women are less than proportionally represented (as in the last two sections of the first row). ${ }^{13}$ This 'equality' or law of communicating vessels implies that for TS to be larger than ES it must be the case that the actual situation $\left(F_{i j}\right)$ and the situation induced by $E S\left(F_{i j}^{\text {educ }}\right)$ are on opposite sides of the ideal distribution. This is shown in the third section of the first row and the first section of the second row in Figure 1. This will mean that relatively more women with a particular education type will be working within a certain occupation compared with the overall ratio, while traditionally, this education type is more readily associated with men, or vice versa. We shall call such a combination of education and occupation an inverse segregation situation. The predicate 'inverse' is used here since the actual distribution is the opposite to what one would expect given presorting (ES). In Section $V$ we see that this is not a rare phenomenon: it occurs in $30.2 \%$ of all cases (see Table 6 ).

To illustrate (19) and (20), assume that one third of the labour force is female so that for all (i,j), $M_{i j}^{\text {equal }} \square 2 F_{i j}^{\text {equal }}$. Suppose that the councils of all economic departments within universities adopt a rather ambitious AAP stating that half of the staff must be female economists. Given an overall female participation rate of $1 / 3$, the ideal distribution indicates that only $1 / 3$ of all staff have to be female. If only 1 out of 10 of all employed economists are female, we would expect the share of female economists in economics departments to be just $10 \%$. Figure 2 depicts this state of affairs. Initially female economists are distributed over both occupations according to their educational share. Since female trained economists will become overrepresented in universities if the programs succeeds $\left(F_{i j}^{\square}>F_{i j}^{\text {equal }}>F_{i j}^{\text {educ }}\right)$, they must be underrepresented elsewhere (e.g. in higher commercial professions which also recruit economists). Note that, whatever the goal of the AAP adopted, $F_{i j}^{\text {educ }}$ and $F_{i j}^{\text {equal }}$ are fixed (the overall and the 'economic' female participation rates of the labour force will not change in the short term due to the AAP). The further $F_{i j}^{\square}$ moves

13. To understand (20), note that ES measures the unequal distribution of men and women over educations, irrespective of the occupations they have chosen. As a consequence, the actual ES of the labour force and the ES of a distribution where $F_{i j} \square F_{i j}^{\text {educ }}$ as with (10) and (11) are equal. 
to the right, the further $F_{i k}^{\square}$ moves to the left. Taking all this together, the AAP proves to be too ambitious and increases AS, OS and TS with ES remaining constant. ${ }^{14}$ Thus the lower contribution of $(\mathrm{i}, \mathrm{j})$ to TS and OS is more than offset by the higher contribution of $(\mathrm{i}, \mathrm{k})$ since the sum of the increases outweighes the decrease.

Figure 2

Affirmative action in occupation $\mathrm{j}$ concerning workers with a male type of education $\mathrm{i}$
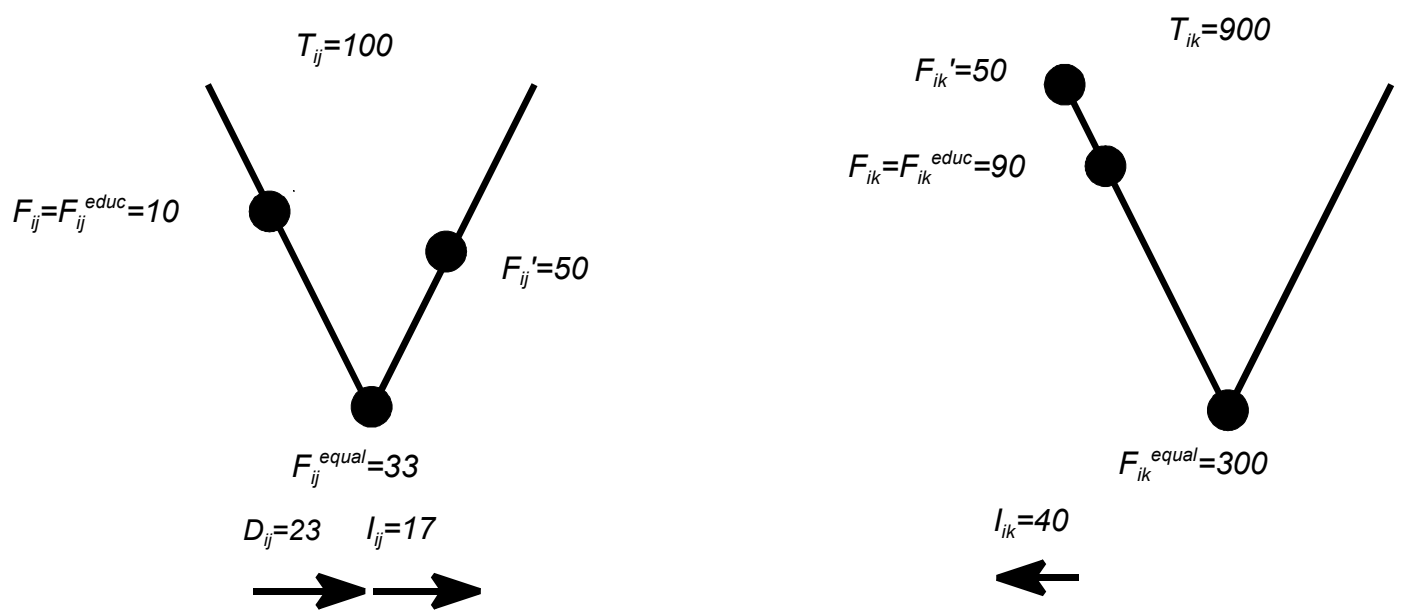

$$
\begin{aligned}
& A S=0 ; A S^{\prime}=I+D=((17+40)+23) / 1000 \\
& T S=(23+210) / 1000=233 / 1000 \\
& T S^{\prime}=(17+250) / 1000=267 / 1000 \\
& E S=E S^{\prime}=233 / 1000 ; \\
& O S=(23 / 1000+(210 / 1000)=233 / 1000 \\
& O S^{\prime}=(17 / 1000)+(250 / 1000)=267 / 1000 \\
& T S^{\prime}=E S^{\prime}+I-D=267 / 1000
\end{aligned}
$$

\section{Total versus occupational segregation}

Equations (19) and (20) relates TS, ES and AS to each other. Nevertheless, the question of how these relate to OS is still unanswered. OS is always less than or equal to TS, and this can be derived as follows:

OS is strictly smaller because in any occupation where there are relatively more women than men male workers will be employed from education groups where there are relatively more men. To calculate the extent of this effect on each occupation, TS has to be divided into a male and a female component:

14. If the more modest goal of $F_{i j}^{\square} F_{i j}^{\text {equal }}$ was chosen, then OS, TS and ES would remain constant while AS would become positive. TS (and OS) remain constant because any increases exactly offset any decreases. 


$$
\begin{aligned}
& \text { OS } \square \theta_{j \square 1}^{m} F_{j . j} \square \frac{M_{. j}}{M_{. .}}
\end{aligned}
$$

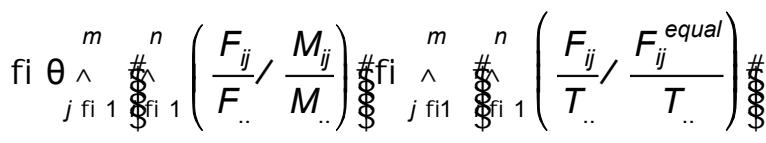

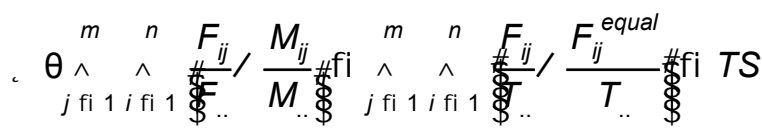

and

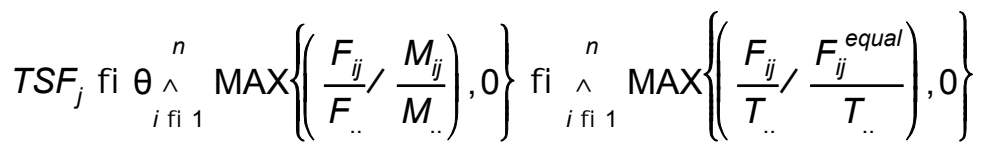

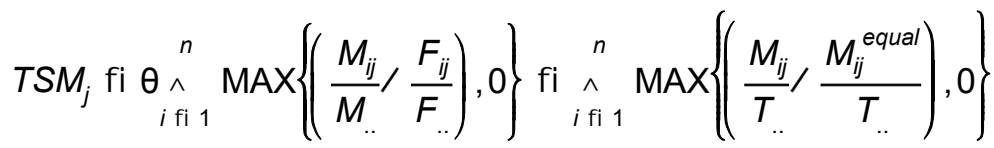

Equation (22) measures the overrepresentation of women compared to men for all $i$ in occupation $\mathrm{j}$, given the overall female participation rate. Suppose that occupation $\mathrm{j}$ represents those higher teaching professions where women are overrepresented. Further assume that these teachers are mainly recruited from the higher social and cultural education groups where women are also overrepresented. Then (22) measures women's overrepresentation for the particular combination $(\mathrm{i}, \mathrm{j})$. However, it may be the case that some of the male teachers recruited come from educational backgrounds $h \mathrm{~g} i$ where men are overrepresented (e.g. theology). This is measured by (23). Since most workers in j are female and recruited from predominantly female types of education, $T S F_{j}>T S M_{j} . T S M_{j}$ is therefore the smaller of the two and measures all instances where relatively more men than women work within this tradionally female occupation. The elimination of the absolute operators in (21) causes the $j$-th component of TS to fall by an amount equal to twice $T S F_{j}$ or $T S M_{j}$, whichever is the smallest. This occupation-specific factor of reintegration $R_{j}$ is responsible for the difference between $O S_{j}$ and $T S_{j}$ : it takes OS below TS.

and therefore:

$$
O S_{j} \square T S_{j} \square 2 \mathrm{MIN}\left\{T_{S F_{j}}, T S M_{j}\right\} \square T S_{j} \square R_{j}
$$

$$
\text { OS } \square T S \square R
$$

Figure 3 illustrates this reintegration. Initially all workers in occupation j are recruited from the predominantly male type of education $\mathrm{h}$. In the next situation, females are recruited from a female type of education i, keeping the number of workers constant. As shown, even though TS increases, OS decreases due to reintegration. Here, the difference between TS and OS exactly equal to twice the amount of reintegration. This simple example shows that AAP's based on reintegration can be very effective in reducing OS, even to levels below the 
pre-existing amount of ES. If such AAP's can be carried out succesfully, part of the impact of ES on OS can be neutralized.

Figure 3

Reintegration of women with a female type of education $\mathrm{i}$ and men with a male type of education $\mathrm{h}$ into occupation j
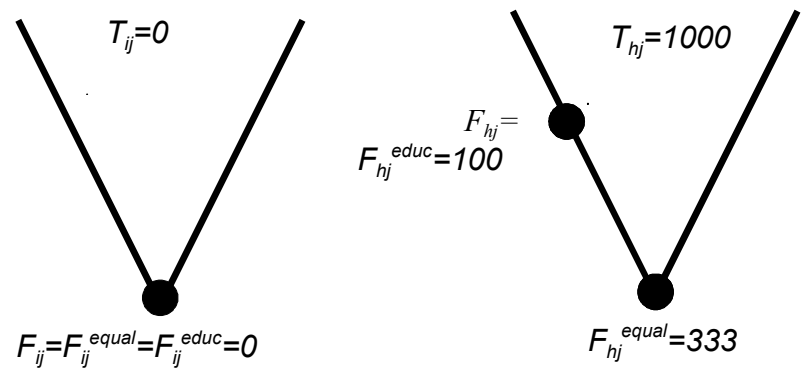

$A S=0$

$T S=233 / 1000$

OS $=233 / 1000$

$T S F_{i}=0$

$T S M_{j}=(900-667) / 1000=233 / 1000$

$R_{j}=0$

$E S=E S_{i}+E S_{h}=0+233 / 1000=233 / 1000$

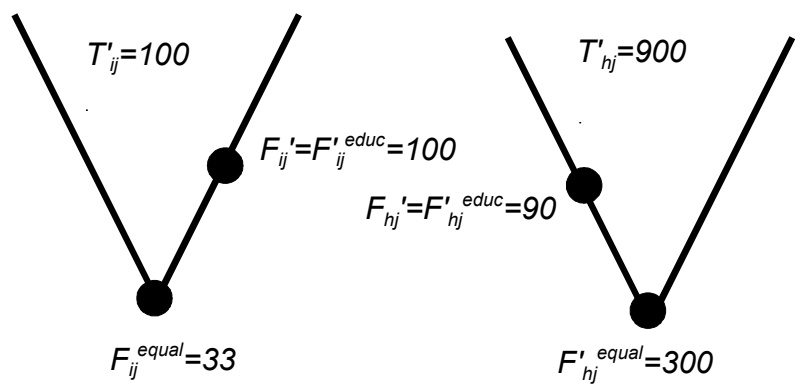

$A S^{\prime}=0$

$T S^{\prime}=(67+210) / 1000=277 / 1000$

$O S^{\prime}=A B S((67-210) / 1000)=143 / 1000$

$T S F^{\prime}=67 / 1000$

$T S M^{\prime}=210 / 1000$

$R^{\prime}=2(67 / 1000)=134 / 1000$

$O S^{\prime}=T S^{\prime}-R^{\prime}$

$E S^{\prime}=(67+210) / 1000=277 / 1000$

Equations (19), (20) and (25) show the relationships between the different measures of segregation. Substituting (25) in (20) gives:

(26) OS $\square E S \square I \square D \square R$

The following section illustrates equation (26) empirically.

\section{Empirical Results}

In this section we examine the path from educational to occupational segregation in The Netherlands. The link between OS and ES which was identified in the previous section shows that there are two main steps when moving from ES to OS. Firstly inverse segregation means that the distribution of those people with a particular educational background over the various occupations may be such that both OS and TS increase. Such an increase is only possible if within certain occupations more men than women are employed from a female type of education (i.e. an education type with more than $50 \%$ women) or more women than men are employed from a male type of education (as in Figure 2). This implies that OS and TS will not increase if the ratio of male to female 
workers within certain occupations with a particular educational background changes, so long as the majority group remains the majority group. An employer who employs more women than men from an educational type which is known to be male may therefore appear to be involved in a desegregation process, but his/her behaviour is in fact forcing other employers to employ the remaining men. Desegregation arising from an inverse segregation situation will therefore force others to increase segregation. The combined effect of these inverse segregation situations though, is always to worsen both OS and TS.

The second step in the channel from ES to OS may contribute to the process of desegregation. By employing women from a female type of education and men from a male type of education for one occupation, OS decreases.

Table 4

Educational segregation (ES) by type of education in 1985 and 1993/94

\begin{tabular}{|c|c|c|}
\hline & $\begin{array}{l}\text { ES } \\
1985 \\
\%\end{array}$ & $\begin{array}{l}\text { ES } \\
1993 / 94 \\
\%\end{array}$ \\
\hline Primary Education & $\square 2.4$ & $\square 6.1$ \\
\hline Lower General Secondary Education & 15.6 & 12.7 \\
\hline \multicolumn{3}{|l|}{ Lower Vocational Education } \\
\hline Agriculture & $\square 29.9$ & $\square 28.8$ \\
\hline Technical & $\square 28.4$ & $\square 31.6$ \\
\hline Transport \& Harbour & $\square 31.9$ & $\square 34.1$ \\
\hline Commerce \& Administration & 26.3 & 23.3 \\
\hline Community Care, Hotel \& Catering & 55.5 & 53.8 \\
\hline Security & $\square 28.1$ & $\square 29.8$ \\
\hline Higher General Secondary Education & 9.1 & 8.6 \\
\hline \multicolumn{3}{|l|}{ Intermediate Vocational Education } \\
\hline Agriculture & $\square 27.8$ & $\square 25.7$ \\
\hline Non-Medical laboratory & $\square 17.4$ & 0.3 \\
\hline Engineering & $\square 30.5$ & $\square 30.4$ \\
\hline Transport \& Harbour & $\square 24.7$ & 26.3 \\
\hline Medical Laboratory & 38.3 & 40.8 \\
\hline Nursing \& Para-medical services & 52.8 & 52.6 \\
\hline Commerce \& Administration & 20.1 & 6.7 \\
\hline Administrative, Legal \& Fiscal & $\square 20.3$ & $\square 12.4$ \\
\hline Social \& Cultural & 18.8 & 31.9 \\
\hline Community Care & 58.5 & 46.0 \\
\hline Hotel, Catering \& Hairdressing & 13.1 & 17.6 \\
\hline Police, Fire \& Defense Forces & $\square 29.5$ & $\square 30.6$ \\
\hline
\end{tabular}


Table 4 (continued)

Educational segregation (ES) by type of education in 1985 and 1993/94

\begin{tabular}{lll}
\hline & ES & ES \\
& 1985 & $1993 / 94$ \\
& $\%$ & $\%$ \\
\hline
\end{tabular}

Higher Vocational Education

Teacher Training

Interpreter \& Translator

Theology

Agriculture

Non-medical Laboratory

Engineering

Higher Transport \& Harbour

Medical Laboratory

Nursing \& Physiotherapy etc.

Commerce \& Administration

Business Administration Technology

Administrative, Legal \& Fiscal

Social \& Cultural

Hotel \& Catering Industry

Fine Arts

Police, Fire \& Defense Forces

Academic Education

Teacher Training

Arts

Theology

Agriculture

Mathematics \& Natural Sciences

Engineering

Veterinary \& Medical Sciences \& Dentistry

Pharmacy

Economics, Econometrics \& Business Administration

Law \& Public Administration

Social Sciences

Fine Arts
16.3

20.8

$\square 20.7$

$\square 28.9$

$\square 11.4$

$\square 32.3$

$\square 30.3$

36.6

34.6

7.2

$\square 25.6$

$\square 23.2$

15.4

$\square 11.5$

$\square 1.2$

$\square 32.7$

$\square 10.4$

5.9

$\square 26.2$

$\square 19.0$

$\square 19.5$

$\square 31.9$

$\square 11.8$

$\square 6.8$

$\square 27.1$

$\square 12.5$

$\square 0.5$

9.9
18.8

23.5

$\square 26.6$

$\square 22.2$

$\square 6.3$

$\square 33.7$

$\square 33.2$

35.7

34.8

5.8

$\square 28.5$

$\square 17.0$

20.4

0.0

2.7

$\square 31.0$

Table 4 shows ES for 49 education types in 1985 and 1993/94. ${ }^{15}$ The table provides relative

15. Five residual categories - one for each educational level and one general residual category have been excluded from the table, but are nevertheless incorporated in the analysis. 
figures so that they become mutually comparable (see footnote 6). Negative segregation indices mean that more men than women have the educational background indicated, that is women are underrepresented. From the results, it follows that the most extreme cases of ES are found in some female types of education. Lower and intermediate vocational education that prepares for community care and hotel/catering services along with intermediate vocational education that prepares for nursing and paramedical services have relative segregation indices of more than $50 \%$. Some typical male types of education appear to be all vocational education preparing for transport and harbour occupations and higher vocational education preparing for engineering, the police/fire services and defence forces. These male types of education have a relative segregation index below $\square 30 \%$. The table also gives information on the changes in ES that have occured between the 1985 and $1993 / 1994$ period. On average, these changes have been small illustrating that ES in the labour force can be considered to be fixed in the short term. For academic education, women's overrepresentation increased in the arts subjects and the social sciences, while men's overrepresentation decreased sharply in subjects such as law and public administration.

Table 5 shows how OS relates to ES in 1985. The first to the fifth column describes the route from ES to OS. The sixth column shows OS in 1993/94. All these figures are relative figures. The relative ES per occupation measures the ES of all workers employed within this particular occupation. Again, some female occupations provide the most extreme examples. Intermediate medical and paramedical professions have an ES of $42 \%$ and the index for intermediate service occupations is equal to $34 \%$. Since one of these occupations brings people from different education types together, these extremes are smaller than those in the case of ES per se. Some extreme examples of male occupations are the intermediate police, fire and security occupations (26\%) and the intermediate military occupations $(25 \%)$.

In practice, however, the sex distribution over the various occupations differs from the educational sex ratios. In some educational categories that prepare for a particular occupation segregation decreases, while in others it increases. These deviations are reported in the second and third columns. As shown in the previous section, any increases in segregation due to the postsorting process will always dominate any decreases. For most occupations it is, in accordance with this general rule, found that any increase in segregation is larger than any decrease. The only exceptions to this rule occur with the lower textile occupations, the higher medical and paramedical occupations, intermediate socio-cultural occupations and the intermediate hotel and catering occupations. This implies that these four occupations tend to employ workers with different educational backgrounds in ratios which are closer to the ideal distribution than ES suggests (see the upper left and lower right sections of Figure 1). Other occupations therefore have to accept more extreme proportions of women or men. In 1993/94 the number of occupations where decreases in segregation were larger than increases was equal to 10 . Therefore, there seems to be a tendency in many occupations to 'correct' the distribution induced by ES. 
Table 5

Occupational segregation derived from pre- and postsorting (OS = ES + I - D - R). (-) indicates educational overrepresentation of men

\begin{tabular}{|c|c|c|c|c|c|c|}
\hline $\begin{array}{l}\text { Educ } \\
\text { segr }\end{array}$ & $\begin{array}{r}1985 \\
\text { tional } \\
\text { gation } \\
\%\end{array}$ & $\begin{array}{r}\text { Increase } \\
\%\end{array}$ & $\begin{array}{r}\text { Decrease } \\
\%\end{array}$ & $\begin{array}{r}\text { Reintegration } \\
\%\end{array}$ & $\begin{array}{r}1985 \\
\text { Occupational } \\
\text { segregation } \\
\%\end{array}$ & $\begin{array}{r}1993 / 94 \\
\text { Occupational } \\
\text { segregation } \\
\%\end{array}$ \\
\hline lower food and beverage occupations (-) & 19.6 & 11.4 & 2.6 & 3.0 & $\square 25.5$ & $\square 21.9$ \\
\hline lower textile occupations & 22.1 & 4.8 & 11.4 & 1.3 & 14.1 & 14.3 \\
\hline lower wood and paper occupations (-) & 23.3 & 10.0 & 0.7 & 0.4 & $\square 32.3$ & $\square 34.8$ \\
\hline lower printing industry occupations (-) & 21.7 & 6.5 & 2.4 & 5.8 & $\square 20.0$ & 16.4 \\
\hline lower chemical industry occupations (-) & 20.5 & 11.2 & 3.1 & 2.3 & $\square 26.3$ & $\square 28.8$ \\
\hline lower metals industry occupations (-) & 22.9 & 10.1 & 1.2 & 0.6 & $\square 31.1$ & $\square 33.1$ \\
\hline lower technical and industrial occupations (-) & 17.3 & 16.8 & 1.3 & 0.2 & $\square 32.6$ & $\square 36.0$ \\
\hline lower agricultural occupations (-) & 23.5 & 5.1 & 1.7 & 12.1 & $\square 14.8$ & $\square 16.7$ \\
\hline lower electrical occupations (-) & 20.4 & 2.4 & 1.7 & 15.4 & $\square 5.7$ & 07.2 \\
\hline lower service occupations & 28.3 & 25.3 & 2.8 & 0.8 & 50.1 & 45.1 \\
\hline lower building materials industry occupations (-) & 17.3 & 14.0 & 2.1 & 4.7 & $\square 24.5$ & $\square 27.4$ \\
\hline lower construction and installation occupations (-) & 18.9 & 14.6 & 1.3 & 0.2 & $\square 32.0$ & 11.2 \\
\hline lower hotel and catering occupations & 28.0 & 13.2 & 13.1 & 1.3 & 26.8 & 19.9 \\
\hline lower transport occupations (-) & 16.6 & 5.5 & 2.9 & 10.8 & $\square 8.4$ & $\square 9.3$ \\
\hline lower marine and inland waterway occupations (-) & 20.0 & 12.7 & 1.9 & 1.1 & $\square 29.7$ & $\square 35.9$ \\
\hline lower sales and purchasing occupations (-) & 22.0 & 19.2 & 3.7 & 0.5 & 37.0 & 25.5 \\
\hline lower road and rail occupations (-) & 18.5 & 15.3 & 3.2 & 0.3 & $\square 30.4$ & $\square 30.4$ \\
\hline lower administrative occupations & 17.9 & 4.4 & 0.9 & 14.4 & 6.9 & $\square 3.1$ \\
\hline intermediate sales and purchasing occupations (-) & 12.6 & 15.0 & 4.2 & 3.0 & $\square 20.3$ & $\square 14.3$ \\
\hline intermediate marine and inland waterways occupations (-) & 22.2 & 10.7 & 0.7 & 0.6 & $\square 31.6$ & 036.3 \\
\hline intermediate air and miscellaneous transport occupations (-) & 18.3 & 15.7 & 3.2 & 0.4 & $\square 30.5$ & $\square 31.2$ \\
\hline intermediate medical and paramedical occupations & 42.0 & 8.9 & 1.2 & 0.9 & 48.8 & 47.2 \\
\hline intermediate administrative occupations & 14.3 & 13.2 & 1.1 & 4.5 & 21.9 & 24.7 \\
\hline intermediate hotel and catering occupations (-) & 19.1 & 7.2 & 11.1 & 12.6 & $\square 2.6$ & 5.1 \\
\hline
\end{tabular}


Table 5 (continued)

Occupational segregation derived from pre- and postsorting (OS = ES + I - D - R). (-) indicates educational overrepresentation of men

\begin{tabular}{|c|c|c|c|c|c|c|}
\hline & $\begin{array}{r}1985 \\
\text { Educational } \\
\text { segregation } \\
\%\end{array}$ & Increase & Decrease & Reintegration & $\begin{array}{r}1985 \\
\text { Occupational } \\
\text { segregation } \\
\%\end{array}$ & $\begin{array}{r}1993 / 94 \\
\text { Occupational } \\
\text { segregation } \\
\%\end{array}$ \\
\hline intermediate service occupations & 33.7 & 14.1 & 4.2 & 0.6 & 43.0 & 47.1 \\
\hline intermediate police, fire, and security occupations (-) & 26.0 & 5.0 & 1.8 & 0.9 & $\square 28.2$ & $\square 26.2$ \\
\hline intermediate military occupations (-) & 25.0 & 11.1 & 4.1 & 0.0 & $\square 32.0$ & $\square 33.0$ \\
\hline intermediate technical and industrial occupations (-) & 22.8 & 8.3 & 2.5 & 1.2 & $\square 27.4$ & $\square 25.7$ \\
\hline intermediate mechanical trades $(-)$ & 27.1 & 6.5 & 0.6 & 0.2 & $\square 32.8$ & $\square 35.2$ \\
\hline intermediate sports occupations & 20.6 & 9.0 & 6.0 & 7.7 & 15.9 & 2.9 \\
\hline intermediate art \& design trades (-) & 15.5 & 10.6 & 6.1 & 12.8 & $\square 7.1$ & $\square 2.2$ \\
\hline intermediate electrical trades (-) & 27.4 & 6.0 & 0.8 & 1.0 & $\square 31.5$ & $\square 33.6$ \\
\hline intermediate construction and installation trades (-) & 28.7 & 4.8 & 1.4 & 0.1 & $\square 31.9$ & $\square 33.6$ \\
\hline intermediate socio-cultural occupations (-) & 13.7 & 5.8 & 8.0 & 8.6 & $\square 2.8$ & 4.4 \\
\hline higher administrative professions (-) & 14.9 & 15.4 & 4.3 & 0.2 & $\square 25.8$ & $\square 21.9$ \\
\hline higher legal and government professions (-) & 15.4 & 5.8 & 2.3 & 0.7 & $\square 18.3$ & $\square 6.7$ \\
\hline higher medical and paramedical professions & 25.0 & 2.6 & 4.1 & 11.4 & 12.1 & 13.6 \\
\hline higher commercial and administrative professions (-) & 15.2 & 18.1 & 5.9 & 2.5 & $\square 24.9$ & $\square 19.5$ \\
\hline higher socio-cultural professions & 14.0 & 4.4 & 2.0 & 4.4 & 12.0 & 20.2 \\
\hline higher construction and installation professions (-) & 30.6 & 2.6 & 1.1 & 1.1 & $\square 30.9$ & $\square 32.0$ \\
\hline higher electrical professions (-) & 30.3 & 3.9 & 0.6 & 0.0 & $\square 33.5$ & $\square 35.7$ \\
\hline higher mechanical and metals industry professions (-) & 30.1 & 4.1 & 0.7 & 0.0 & $\square 33.5$ & $\square 35.5$ \\
\hline higher teaching professions & 16.4 & 2.4 & 2.3 & 5.5 & 11.0 & 10.1 \\
\hline higher literary professions & 11.9 & 19.9 & 0.4 & 3.3 & 28.1 & 29.2 \\
\hline higher theological vocations (-) & 22.9 & 8.4 & 1.1 & 4.6 & $\square 25.7$ & $\square 19.8$ \\
\hline higher professions in the arts and design & 9.3 & 6.0 & 3.9 & 5.9 & 5.5 & 2.9 \\
\hline higher agricultural professions (-) & 25.1 & 5.0 & 0.2 & 1.3 & $\square 28.6$ & $\square 22.6$ \\
\hline higher technical and industrial professions (-) & 24.0 & 4.3 & 1.5 & 0.9 & $\square 25.9$ & $\square 23.7$ \\
\hline
\end{tabular}


An overall reduction of OS is only possible through reintegrations. Table 5 shows that some occupations will to a large extent combine female workers from female types of education with male workers from male types of education. The most important instances of reintegration occur in lower electrical occupations, lower agricultural occupations, lower administrative occupations and intermediate hotel and catering occupations. It may seem surprising that the largest reintegration of men and women occurs in the lower electrical occupations. This occupation involves tasks which include the assemblage of printed circuit boards, a job which is often fulfilled by women. In fact this job has no specific skill requirements. It is therefore possible that men are recruited from the lower technical education groups, while women are recruited from other lower vocational education groups where they are overrepresented. The high reintegration component in the other occupations is less surprising. Many lower agricultural and administrative occupations and jobs in hotel and catering services may be filled by both men and women with different educational backgrounds as they are able to learn the job specific skills required.

Table 6

Frequency of the ordering of $F_{i j}^{e q u a l}, F_{i j}^{e d u c}$ and $F_{i j}$ in 1985

\begin{tabular}{lcl} 
ordering & $\%$ & description \\
\hline$F_{i j}^{\text {educ }}<F_{i j}<F_{i j}^{\text {equal }}$ & 8.1 & $\begin{array}{l}\text { decreased segregation of a male } \\
\text { type of education } \\
\text { increased segregation of a male }\end{array}$ \\
$F_{i j}<F_{i j}^{\text {educ }}<F_{i j}^{\text {equal }}$ & 37.0 & $\begin{array}{l}\text { type of education } \\
\text { inverse segregation of a female }\end{array}$ \\
$F_{i j}<F_{i j}^{\text {equal }}<F_{i j}^{\text {educ }}$ & 24.5 & $\begin{array}{l}\text { type of education } \\
\text { inverse segregation of a male type } \\
\text { of education }\end{array}$ \\
$F_{i j}^{\text {educ }}<F_{i j}^{\text {equal }}<F_{i j}$ & 5.7 & $\begin{array}{l}\text { increased segregation of a female } \\
\text { type of education } \\
\text { decreased segregation of a } \\
\text { female type of education }\end{array}$ \\
$F_{i j}^{\text {equal }}<F_{i j}^{\text {educ }}<F_{i j}$ & 17.0 & 7.6
\end{tabular}

Presorting due to ES, increases and decreases in segregation and reintegration all result in OS. The segregation in the lower service occupations, i.e. typical female occupations, is largely due to postsorting. Here, the index for presorting due to ES is equal to 0.28. Postsorting adds 0.25 and subtracts 0.03 from this, while reintegration only diminishes the segregation by 0.01 . However, for the intermediate medical and paramedical occupations, which are also typically female in nature, segregation is mainly due to presorting. Occupations which are typically male in nature include those in the higher mechanical and metals industries and higher technical professions. Segregation here is mainly due to 
presorting. However, segregation in the lower technical and industrial occupations is largely due to postsorting. As stated, an increase in segregation is only possible if certain combinations of occupation and education type lead to inverse segregation. Table 6 provides information about the frequency of all situations (corresponding to the six sections of Figure 1). The frequency among all $(\mathrm{i}, \mathrm{j})$ where the fraction of male workers coming from a female type of education in some particular occupation exceeds the overall participation fraction of men and vice versa is $24.5 \%$ and $5.7 \%$ respectively. Hence, almost one third of all $(\mathrm{i}, \mathrm{j})$ are characterized by inverse segregations.

If $F_{i j}^{\text {educ }}$ is less than $F_{i j}^{\text {equal }}$, then education $\mathrm{i}$ is predominantly male (see equations (10) to (13) above). The third and fourth rows of the table show that inversions are more frequent for female than male education types. ${ }^{16}$ Many occupations tend to employ men rather than women from these female types of education. The frequency among all $(i, j)$ is even higher than the more 'usual' orderings of female types of education where there is an increase or decrease in segregation (the two lower right sections of Figure 1). For male types of education, this tendency is less strong. But still, in more these $5 \%$ of all cases this situation occurs. Finally, there are more cases where there are only increases in segregation $(37 \%+$ $17 \%)$ than where there are only decreases in segregation $(8.1 \%+7.6 \%) .^{17}$

Table 7

The link between educational and occupational segregation from 1979 till 1985

$1979 \quad 1981 \quad 1983 \quad 1985 \quad 1993 / 94$

$\begin{array}{lrrrrr}\text { Educational segregation } & 17.9 & 18.5 & 19.9 & 20.8 & 21.6 \\ \text { Increase } & 12.0 & 12.2 & 12.0 & 11.4 & 10.0 \\ \text { Decrease (-) } & 2.4 & 2.2 & 2.4 & 2.7 & 3.3 \\ \text { Reintegration (-) } & 2.8 & 3.1 & 3.4 & 3.4 & 4.5 \\ \text { Occupational segregation } & 24.8 & 25.2 & 26.0 & 25.9 & 23.8\end{array}$

Table 7 shows the segregation indices at an aggregated level for the 1979-1993/94 period. While ES increased during these years, OS decreased. Therefore, the gap between ES and OS decreased from $6.9 \%$ in 1979 to $2.2 \%$ in $1993 / 94$. This is equal to the net effect of the increase, decrease and reintegration which together are responsible for the gap. The increase in segregation due to postsorting fell by $2 \%$ to $10 \%$, and the decrease rose by

16. This means that for all $(\mathrm{i}, \mathrm{j})$ the upper right section of Figure 1 prevails more often than the lower left section.

17. Increases only occur in the two middle pictures of Figure 1 where there are movements away from the distribution induced by educational segregation as well as from the ideal distribution. Decreases only occur in the upper left and lower right sections, which represent movements away from the distribution induced by educational segregation but towards the ideal distribution. 
$0.9 \%$. Finally, reintegration increased sharply by $1.7 \%$. In the previous sections we distinguished between two components of postsorting. The first component, i.e. the degree to which women and men with the same type of education are directed towards different occupations (measured by the combined impact of any increase and any decrease), may enlarge the gap between ES and OS. This now becomes less important. The second component, namely reintegration, i.e. the bringing together of sexes with different educational backgrounds into the same occupations and thus narrowing the gap, now becomes more important.

It must be remembered that part of the increase in ES and decrease in OS can be due to the replacement of older generations by younger ones. The OS among retiring men and women of older generations is perhaps higher, while the ES is lower than those of the younger generations. This suggests that presorting becomes more important, that is educational choices become more and more connected to the occupational possibilities that exist afterwards, while the first component of postsorting becomes far less important. Given the more or less tight connections between predominantly vocational educations and specific occupations, men and women choosing particular directions during their educational career may explain the increase in presorting on the one hand and the decrease in the net effect of postsorting on the other.

It may be reasonable to expect that a high degree of both ES and OS will be with us for at least the next two decades. Still, some specific policy measures can be undertaken in order to attenuate these segregations. Firstly, governments can take special measures to increase the number of the underrepresented group in educations where there is a high sexsegregation among students. This policy bears fruit in the long term only. In the short term, the government can try to motivate employers to recruit more women (men) with a predominantly female (male) background into typically male (female) jobs. These reintegration-based AAP's can be very effective, whereas short-sighted AAP's are of no avail, at least in the short term.

\section{Conclusions}

The main aim of this paper was to disentangle the relationship between ES and OS, and in doing so, investigate whether OS between men and women is predetermined by educational presorting. We can safely conclude that ES is still a major cause of OS. There are, theoretically, two processes responsible for the difference between ES and OS. Firstly, employers might employ workers with a certain educational background for jobs with a ratio that deviates from the actual educational ratio. This process of postsorting, namely additional segregation, can in the aggregate only lead to increases in both TS and OS, provided the situation is one of inverse segregation. This is a situation where the ratio of men and women within a particular occupation does not correspond with the ratio of the men 
and women within the educational group from which they descend. Such inverse segregation situations occur quite often. Over-ambitious (and ineffective) AAP's can lead to situations of inverse segregation. Our analysis has found that the net effect of this type of postsorting decreased between 1979 and 1993/94.

Secondly, segregation may be reduced by employing both men from male types of education and women from female types of education in one occupation. The relative importance of this process, which we termed reintegration, increased between 1979 and $1993 / 94$, but the extent of this reintegration is still quite modest. The combined effects of both these types of postsorting, additional segregation and reintegration, is too small to counterbalance the effect of ES on OS. Over time however, ES tends to rise while OS becomes smaller. The reduction of the gap between ES and OS is due to both a decrease in postsorting and an increase in reintegration. As a final point, the method which we have developed can be used whenever one is able to distinguish between two groups, and also when one distribution partly determines another distribution, e.g. when the distributions of children from poor and rich families over educations and occupations differ.

\section{References}

Albelda, R.P. (1986), Occupational Segregation by Race and Gender, 1958-1981, Industrial and Labor Relations Review, 39(3), pp. 404-411.

Becker, G.S. (1973), The Economics of Discrimination, Chicago, University of Chicago Press.

Beller, A.H. (1982), Occupational Segregation by Sex: Determinants and Changes, Journal of Human Resources, 17(3), pp. 371-392.

Blackburn, R.M., J. Siltanen and J. Jarman (1995), The Measurement of Occupational Segregation: Current Problems and a New Approach, Journal of the Royal Statistical Society A, 158(2), pp. 319-331.

Boisso, D. (1994), Occupational Segregation in the Multidimensional Case: Decomposition and Tests of Significance, Journal of Econometrics, 61(1), pp. 161-171.

Corcoran, M. E. and P.N. Courant (1987), Sex-Role Socialization and Occupational Segregation: An Exploratory Investigation, Journal of Post Keynesian Economics, 9(3), pp. 330346.

Duncan, Otis Dudley and Beverly Duncan (1955), A Methodological Analysis of Segregation Indexes, American Sociological Review, 20, pp. 210-217.

Fuchs, V.R. (1989), Women's Quest for Economic Equality, The Journal of Economic Perspectives, 3(1), pp. 25-42. 
Groot, L.F.M. (1990), De onderwijs- en beroepssegregatie tussen mannen en vrouwen in de eerste helft van de jaren tachtig, Tijdschrift voor Arbeidsvraagstukken, 6(4), pp. 4-12.

Karmel, T. and M. Maclachlan (1988), Occupational Sex Segregation. Increasing or Decreasing?, Economic Record, 64(186), pp. 187-195.

King, M.C. (1992), Occupational Segregation by Race and Sex, 1940-88, Monthly Labour Review, 115(4), pp. 30-37.

Olson, P. (1990), The Persistence of Occupational Segregation: A Critique of its Theoretical Underpinnings, Journal of Economic Issues, 24(1), pp. 161-170.

Phelps, E.S. (1972), The Statistical Theory of Racism and Sexism, American Economic Review, 62 , pp. 659-661.

Polachek, S.W. (1981), Occupational Self-Selection: A Human Capital Approach to Sex Differences in Occupational Structure, The Review of Economics and Statistics, 63(1), pp. 60-69.

Watts, M. (1992), How Should Occupational Sex Segregation be Measured?, Work, Employment and Society, 6(3), pp. 475-487.

Watts, M. and J. Rich (1993), Occupational Sex Segregation in Britain, 1979-1989: The Persistence of Sexual Stereotyping, Cambridge Journal of Economics, 17(2), pp. 159-177.

Willems, E.J.T.A. and A. de Grip (1994), Young People and Technology: Choice of Course of Study and Profession, Evaluation and Image with regard to Technology, Beleidsstudies Technologie Economie 26a, Ministry of Economic Affairs, The Hague. 